\title{
Reflexões antimonotônicas na história da metafísica
}

\author{
Gregory Carneiro ${ }^{1}$
}

\section{RESUMO}

A história da metafísica é povoada com entidades de todos os tipos e que serviram para fundamentar as mais diversas questões filosóficas. A história da humanidade, da mesma maneira, parece criar instrumentos que se colocam dentro de nossas relações e cujo desempenho não é compreendido completamente. O formato pouco sensível às modificações de argumentos válidos na lógica clássica, que aprendemos a usar sem questionar, indica que o caminho do homem, de acumulação na metafísica, tem sido pouco entendido. Aparentemente, nada teria de disruptivo no curso da história a criação de mais entidades, valores, dispositivos ou premissas. A história da metafísica, contudo, pode ser contada de maneira completamente diferente, com atenção direta nestas adições, nestes suplementos. A questão final é saber qual a lógica que nos governa, uma vez que reconhecidas estas entidades que mudam completamente nossa relação com a própria história.

Palavras-chave: Metafísica. Lógica. Virada Linguistica. Suplemento

\section{INTRODUÇÃO}

Existem diversas formas de se contar uma história, real ou obra de ficção. $\mathrm{Na}$ série televisiva Roma (HBO), a história que se tenta passar de maneira original é a da queda da república romana, iniciada por Júlio César e levada à cabo por Otávio Augusto. O enredo geral da série é mesmo conhecido em todos os livros de história antiga. O crescimento da popularidade de Júlio César nos anos que antecedem o nascimento de cristo somado a crescente desigualdade social nas províncias e em Roma e a deterioração do sistema político-jurídico faz com que ecloda uma guerra civil. Após derrota definitiva de Pompeu, algum tempo de governo de Roma como ditador, Júlio César é assassinado por senadores romanos nos idos de março. Após a eclosão de nova guerra civil para a disputa do poder vago em Roma, Otávio Augusto, filho de Júlio César por força de testamento, e Marco Antônio saem vencedores. As relações pelo poder entre os dois se deteriora durante o triunvirato, que envolvia Lépidos, membro da nobreza romana, e, em nova guerra civil, Otávio Augusto retoma o poder de seu pai como ditador e faz reformas que conduziriam

\footnotetext{
${ }^{1}$ Doutorando - Departamento de Filosofia-UnB
} 
Roma para um período de grande estabilidade política, prosperidade econômica e, claro, o fim definitivo da república romana.

A sacada do roteiro da série de TV, para que não fosse mais uma encenação pura e simples de Plutarco, é contar tudo viés de dois soldados rasos, Titus Pulo e Verenus, que na historiografia original romana são brevemente mencionados nos diários de Júlio César da guerra da galícia². Por causa desses dois personagens, tudo muda na apresentação e, argumentamos aqui, na relação com a história de um período consagrada na história humana.

Um caso curioso desta nova roupagem que o fim da república romana é o naufrágio da frota que levava reforços para as tropas de Júlio César que estava em situação complicada na Grécia e prestes a enfrentar Pompeu na batalha decisiva. Únicos sobreviventes do desastre e perdidos em uma praia, Verenus e Pulo encontram Pompeu já em rota de fuga após a batalha decisiva, na qual tinha saído derrotado apesar da vantagem inicial. Mesmo podendo prender Pompeu e receber recompensas entregando-o para Júlio César como prisioneiro de guerra, os dois soldados protagonistas da série de TV decidem libertar Pompeu para que continuasse sua fuga para o Egito. Essa deliberada libertação culmina com a morte de Pompeu a mando dos homens de Ptolomeu, até então governador do Egito e vassalo de Roma. Tal fato leva Júlio César para o Egito, que tira Ptolomeu do poder e coloca Cleópatra no lugar.

Outro caso emblemático da série ocorre quando o então Tribuno dos Plebeus, Marco Antônio, aliado de Júlio César, é atacado por homens de Pompeu no caminho para o Senado. Na verdade, esse evento, que iniciou a guerra civil entre Pompeu e Júlio César, era um ataque a Pulo na narrativa da série televisiva, que tinha se envolvido em confusões por causa de jogo com uma das pessoas que acompanhavam a comitiva de Marco Antônio pelo Fórum.

Nenhum destes dois casos encontra respaldo na história romana padrão. Muito provavelmente não ocorreram, embora também não possam ser eventos descartados. Fora de qualquer confrontação arqueológica ou coisa que o valha nas investigações da história romana, somos levados a questionar o que esses dois personagens significam o que nesta nova maneira de contar a história.

Apesar da história da virada romana ser conhecida e consolidada, é curioso chamar atenção para a "revelação" que a narrativa com esses dois personagens traz e a total ressignificação de todo o curso da história que é a narrativa desse período importante. Nesta versão televisiva, a habilidade e a leitura política de César já não é mais a leitura e destreza de antes, pois o elemento do acaso se tornou evidente pela atuação daqueles "peões" da disputa pelo poder na maior e mais complexa

${ }^{2}$ Cf. CÉSAR. La guerre des gaules. Paris, França: GF Flammarion, 1964. 
organização estatal que já existiu na face da terra. Sabemos, de um lado, qual é o sentido da história sem Pulo e Verenus, mas isso já não importa mais. Ainda que tudo seja a fantasia de um roteirista que busca o original, que busca dinheiro da audiência televisiva, ou seja, que seja pura mentira capitalista e feita para distrair, aqueles elementos nos abrem os olhos para algo que não estava lá antes, e, ao invés de serem "temperadas" pelo contexto histórico, muda o contexto como um todo.

A questão que parece relevante e tem sido, de maneira um tanto desconexa e com pluralidade de termos, levantada por muitos filósofos contemporâneos, é que história da metafísica carrega semelhantes dispositivos, conceitos e práticas, que igualmente alteraram o modo das coisas. Não o modo como vemos as coisas, a representação, mas as coisas. Estes dispositivos ainda misteriosos são capazes de alterar os contextos, "ressignificam" o próprio processo de significação, mudam as relações e nos colocam em contato com outros aspectos ainda não revelados dos conceitos. A metafísica está contaminada com um parasita, um hospedeiro capaz de mudar sua composição. O nosso século, aparentemente, é marcado pela impossibilidade de ignorar que nem tudo segue um caminho pacífico do acúmulo positivo. Daí mostrar que as conexões metafísicas entre lógica não é um privilégio da lógica clássica e suas extensões. As lógicas não-clássicas genuínas exigem seu lugar de alguma forma. Não podemos ignorar as modificações que Pulo e Verenus causam no curso da história. Não podemos ignorar as mudanças que as tecnologias trazem para dentro das relações de trabalho, fisiológicas, sentimentais e psicológicas. De maneira geral, não podemos ignorar que algumas premissas mudam completamente nossa relação com antigas e estáveis conclusões. Algumas informações são demais para serem toleradas sem protesto. Talvez o nada seja melhor que a totalidade, se analisarmos de perto.

\section{O CAMINHO}

O primeiro filósofo a fazer esse diagnóstico da história da metafísica é Martin Heidegger. Em A palavra de Nietzsche 'Deus Morreu', parte do livro Os caminhos da Floresta (Holzweg), Heidegger busca descrever a história da metafísica, o pensar da totalidade ${ }^{3}$, no viés do niilismo, e aborda todos os problemas que surgem com o império do suprassensível. O caminhar da ciência de modo geral buscou o ser, mas

\footnotetext{
${ }^{3}$ HEIDEGGER. Os Caminhos da Floresta. Lisboa, PT: Fundação Calouste Gulbenkian, p. 243. 
sem estar junto da verdade do $\operatorname{ser}^{4}$. Na metafísica de Nietzsche, toda a reflexão metafísica culmina na famosa frase "Deus Morreu".

A famosa assertiva de Nietzsche não é uma tese religiosa, na visão de Heidegger. Não se trata de atacar o divino enquanto expressão da fé ou princípio criador. Não é isto que o niilismo busca. A questão primordial é a história da metafísica ou, como é colocado no Holzweg, "o destino de dois milénios de história ocidental"5. O designado, na leitura de Heidegger, é o mundo suprassensível. "Deus é o nome para o âmbito das ideias e dos ideais". O suprassensível é aqui o metafísico ao modo platônico. A filosofia matou a metafísica, tirou a sua força? O caminho para o niilismo é inevitável?

$\mathrm{Na}$ verdade, essa discussão toda é um tanto complicada de se compreender nesse âmbito "das coisas". Como o próprio Heidegger enuncia, a empreitada niilista é de toda filosofia, não só de um campo particular. A ética, nesse sentido, pode nos ajudar a compreender a caminhada niilista heideggeriana para longe do platonismo, dos valores estratificados, imutáveis. É um exemplo mais nítido.

Sabemos que a ética, por quase dois milênios, se concentrou em conceitos de bondade, justiça, correção etc. A ação boa é a ação ética. O ético, por sua vez, é direcionado para esse mundo superior, do padrão das ideias, se o termo usado é platônico. O advento da ética kantiana empurrou tudo para o âmbito da própria ação, da autonomia. A ética kantiana é toda centrada na noção de autonomia. Apenas com essa simples mudança, o mundo ético perde a pujança e superioridade, pois "nada mais permanece a que o homem se possa agarrar, e segundo o qual se possa orientar $^{\prime \prime}$. Vamos pensar agora que a ética contestada por Kant fosse uma ética realista ao modo medieval ${ }^{7}$. Que sobraria para um Deus, que antes ditava e imputava na mente dos homens a bondade, agora que a bondade se encontra na ação dos homens mesmo, por um princípio de autonomia? Deus morreu ou poderia viver, agora sem qualquer influência, pois agora existe a ideia de que Deus pode morrer. Invocamos Kant, mas Heidegger não afasta as próprias reflexões modernas da consciência moral, que também tem o seu aspecto "divinocida"8. O importante é que raparemos na inquietante situação da ética depois do surgimento dos imperativos categóricos: ainda que alguns acreditem que Deus nos diz o certo, nos afaste do mal, o nada nunca mais vai perder seu lugar. "O niilismo (...) está à porta"9.

Os nuances desta negação que o niilismo impõe é de sobremaneira importante. Não se trata de negar o suprassensível, ao modo da negação clássica.

\footnotetext{
${ }^{4}$ Idem. Ibidem., p. 246.

${ }^{5}$ Idem. Ibidem., p. 247.

${ }^{6}$ Idem. Ibidem., p. 251.

7 O que não deixa de ser verdade, uma vez que a ética kantiana se opõe a toda forma de heteronomia.

${ }^{8}$ Idem. Ibidem., p. 255.

${ }^{9}$ Idem. Ibidem., p. 252.
} 
Negar, como um conjunto complemento, é também afirmar, na medida que impõe limites para o conceito negado, e nada contribuiria para o caminhar para o niilismo. Diz Heidegger explicitamente:

"Daí também que o niilismo, no sentido de Nietzsche, de modo nenhum se confunda como o estado, representado de um modo meramente negativo, de já se poder crer no Deus cristão da revelação bíblica (...). Também uma vida não-cristã pode afirmar o cristianismo, e a vida cristã não precisa necessariamente do cristianismo." 10

A confrontação nem sempre inclui o confrontado como algo relevante, assim como premissas adicionadas em argumentos válidos e monotônicos nada mudam, mesmo quando são contraditórios. Este é o gancho que nos levará para Levinas e para uma visão da lógica, em momento oportuno.

Até agora, de maneira resumida, observamos Heidegger usando Nietzsche em movimento filosófico para se afastar de Platão. Isto absolutamente não significa um julgamento direto da qualidade da filosofia platônica. É um caminhar, um "processo fundamental da história ocidental, ao mesmo tempo e antes de mais nada, a legalidade desta história"11. Como ressaltado por Heidegger, o objetivo é dar mais contorno quando lembra de Nietzsche falando que nossa era é a "transmutação de todos os valores" do que quando fala em "desvalorização de todos os valores". Ainda temos metafísica, mas seus conceitos estão se dissolvendo em algo que já não é mais o mesmo. É neste sentido que o niilismo pode ser visto como algo positivo e, qualquer pessimismo, como aspecto da fraqueza ${ }^{12}$. A transmutação não substitui os valores, e sim inverte o modo de se valorar.

Essa percepção do enfraquecimento do suprassensível leva o homem a tomar as coisas com as próprias mãos, invocando o domínio da subjetividade ${ }^{13}$. É a noção de valor que age como um "substituto positivista do metafísico"14, ou seja, do suprassensível como até então concebido. Talvez na época da publicação do Holzweg não fosse evidente a ligação dos valores com a noção de subjetividade. A filosofia contemporânea, contudo, deixa muito claro que valor e ponto de vista são ligados conceitualmente. $O$ valor vale na medida em que seleciona o importante, na medida em que é usado para valorar. Nas palavras de Nietzsche, citado por Heidegger:

\footnotetext{
${ }^{10}$ Idem. Ibidem., p. 254.

${ }^{11}$ Idem. Ibidem., p. 258

${ }^{12}$ Idem. Ibidem., p. 259.

${ }^{13}$ Idem. Ibidem., p. 260.

${ }^{14}$ Idem. Ibidem., p. 262. 
"O valor é o ponto de vista das condições de manutençãoaumento na perspectiva de formações complexas de relativa duração da vida dentro do 'devir'". ${ }^{15}$

Devir enquanto a mudança, o fluir das coisas. O Ente passa a ser determinado pela vontade de poder, pela constante avaliação, que é o novo sentido da metafísica. Em outras palavras, "o niilismo assenta, segundo a interpretação de Nietzsche, no domínio e na desagregação dos valores e, assim, na possibilidade da instauração de valores em geral." 16

Entendamos, então, o que significa essa guinada para a subjetividade. A objetividade do objeto "externo" é suplantada na medida em que valores tomam de assalto a totalidade. A própria subjetividade enquanto ego é garantida pela vontade de poder. Daí que se diz na obra $A$ Vontade de Poder, que "A questão dos valores é mais fundamental que a questão da certeza"17. A supremacia da verdade e outros valores se encontra alterada, segundo Nietzsche. A verdade, tão cara à lógica, às ciências, está ultrapassada e, possivelmente, será atropelada pela vontade de poder.

O esforço constante para sair da metafísica, impor a força do niilismo e invocar a vontade de poder, algo supostamente fora do pensamento metafísico. Entretanto, como pensar o traço essencial da metafísica sem ser metafísico? Nietzsche, segundo Heidegger, não tem uma resposta para essa questão. Não consegue, por conseguinte, sair da metafísica ${ }^{18}$ exatamente por pensar a vontade de poder como traço fundamental do homem - seria um reflexo ainda divino, adestrador do real.

Heidegger, no seu Metaphysics as the History of Being, dá um passo adiante na ideia de subjetividade como base da metafísica. Adiante entre aspas, pois, de maneira declarada, o caminho de Heidegger é um retorno ao seu começo essencial, à presença do Ser, ao seu "whatness" e "thatness". A presença é algo que pressupõe o Ser, que é expressão da existência. Para Heidegger, a essência (ousia) cobra uma existência:

"Being is presence as the showing itself of outward appearance.

Being is the lasting of the actual being in such outward appearance." 19

\footnotetext{
${ }^{15}$ Idem. Ibidem., p. 265.

${ }^{16}$ Idem. Ibidem., p. 268.

${ }^{17}$ Idem. Ibidem., p. 257.

${ }^{18}$ Idem. Ibidem., p. 286.

19 HEIDEGGER. Metaphysics as History of Being in The end of Philosophy. Chicago: The University of Chicago Press, 1973, p. 10.
} 
A presença, dada como Hypokeimenon, enquanto presença de si, obscureceu a essência do Ser no passar para o Subiectum ${ }^{20}$. Este é o ponto que nos liga ao Holzweg e a Vontade de Poder Nietzschiana:

"Subiectum and substans mean the same thing: what is truly constant and real, what suffices for reality and constancy and is therefor called substantia." 21

O subjetivo, assim como a vontade de poder, não é simples expressão de uma vontade pessoal aleatória. É, no fim, o que subjaz (placed under) a metafísica. Não um Ser isolado na sua força representacional, mas uma relação sujeito-objeto sujeito e seu predicado. Embora exista o elemento da percepção, existe apenas para a determinação exata do sujeito 22 .

\section{AS CONFERÊNCIAS}

Nas Conferências de Bremen, novos elementos são colocados na mesa por Heidegger para o pensar sobre a história da metafísica, com instrumentos para pensar como poderíamos reorganizar a metafísica da subjetividade e o papel do niilismo.

Na primeira parte, The Thing, Heidegger chama atenção para o processo paradoxal e danoso de nos afastarmos da proximidade, da vizinhança, nos concentrando apenas em objetos. O processo proposto por Heidegger é de trazer a coisa como coisa de volta para a metafísica, para algo além da representação, mas de uma maneira transversal. Tomemos o exemplo do jarro, usado por Heidegger.

Um jarro, visto de fora, enquanto representação, é apenas um recipiente, algo feito para se colocar líquidos dentro. O que é o recipiente, contudo, é diferente do jarro mesmo, que é o que pode ser experienciado. Só o que é externo pode ser experienciado. Então, o que fazer com a parte que não pode ser experimentada? A sugestão de Kant, nos parece, é ignorar. "Esqueçam da coisa em si", diz o mote kantiano. Esta consideração, afirma Heidegger, "never reaches the thing as thing"23. Aquilo que não é da coisa é o que faz, da coisa, a coisa. No caso do jarro, o vazio não é apenas o que Ihe dá sua utilidade, é o seu vazio que o caracteriza como jarro.

\footnotetext{
${ }^{20}$ Idem. Ibidem., p. 27.

${ }^{21}$ Idem. Ibidem., p. 27.

${ }^{22}$ Idem. Ibidem., p. 38.

${ }^{23}$ HEIDEGGER. Bremen and Freiburg Lecutres. Indiana, USA: Indiana University Press, 2012, p. 7. 
O vazio é parte que é substituída quando algum líquido é colocado no jarro. O nada do jarro é o que acopla o jarro como algo.

Como dito em algumas passagens, o nada, o "que não é o caso" de uma coisa, é algo especial da coisa:

\begin{abstract}
"The jughood of the jug essences in the gift of the pour. Even the empty jug retains its essence from out of the gift, even if an empty jug is not capable of an outpouring. But this "not capable" is appropriate to the jug and to the jug alone. A scythe, on the contrary, or a hammer are incapable of achieving the "not capable" of this gift." 24
\end{abstract}

Daí Hilan Bensusan ${ }^{25}$ afirmar que chegamos na vizinhança de uma coisa apenas quando vemos ela quebrada. Só então temos a dimensão da sua ausência, do que não está disponível. Todo exercício de olhar o jarro é um exercício de compreensão da coisa como coisa, sem nos valermos no imediato da representação - portanto, além do correlacionismo. É preciso nos aproximarmos da coisa e esquecer os objetos. Para achar a coisa na proximidade, diz Heidegger, precisamos considerar a vizinhança do jarro.

A pergunta mais importante neste momento é sobre o que nos coloca em proximidade com a coisa, na sua vizinhança. O tema da proximidade é abordado e outro artigo das Conferências, nomeado Positionality. Heidegger aponta que temos, em geral, a necessidade de eliminar distâncias (Abstandlose) ao abordar objetos como se a distância não existisse, fazendo o objeto se dobrar a nossa maquinação. Posicionar, nesse sentido, não é uma questão de localidade, de coordenadas espaciais, mas de produção, argumenta Heidegger ${ }^{26}$. Conhecer o rio já não é mais um exercício da contemplação. Conhecer é aproveitar seu potencial energético, é navegá-lo, é colocar tudo que o rio tem à disposição. Ao fim, é a transformação da presença da coisa em algo que pode ser ordenado. $O$ mundo se torna algo que obedece a ordens.

Observemos, mais uma vez, que estamos como na relação do conhecedor da história romana com a série da $\mathrm{HBO}$, daquele que conhece a história romana profundamente com a fiç̧ão. Ainda que em casa não façamos uso de energia elétrica, que não tenhamos barco para navegar e assim não exista prejuízo com a mudança do curso das águas, a hidrelétrica muda a nossa relação com o rio. O estado natural da coisa fica em segundo plano.

\footnotetext{
${ }^{24}$ Idem. Ibidem., p. 10.

${ }^{25}$ Comunicação pessoal.

${ }^{26}$ Idem. Ibidem., p. 25.
} 
A "coisa" não é passiva. Logo, nossas relações com as coisas não são estáticas. A tentativa constante do homem de maquinar muda nossas relações ainda que não nos coloquemos intencionalmente nessas relações. O que importa, afinal, é a disposição. O rio passou a ser outro a partir da criação da primeira hidrelétrica. Em trecho um tanto chocante, Heidegger deixa claro como que a eliminação artificial da distância, o uso da tecnologia, faz nossas relações mudarem:

"Agriculture is now a mechanized food industry, in essence the same as the production of corpses in the gas chamber and extermination camps, the same as the blockading and starving of countries, the same as the production of hydrogen bombs"27

Essa Gestell (posicionalidade) é essa ação de ordenação da presença - marca um ponto na história da metafísica. A aproximação com o niilismo na versão heideggeriana parece inevitável neste momento. Os exemplos da citação acima não são por acaso. A Gestell não se confunde com a técnica apenas, com a thecné. Exige, pelo contrário, a maquinação da tecnologia moderna:

"In the age of technological dominance, the humam is placed into the essence of technology, into positionality, by his essence. In his own way, the human is a piece of the standing reserve in the strictest sense of the words 'piece' and 'standing reserve'". ${ }^{28}$

O tanto da "desorganização" da maquinação não transforma tudo em completo caos. O homem, apesar de ser essencialmente colocado em questão pela maquinação, não é ele mesmo uma máquina. Ele produz a máquina. No sentido da negação "incompleta" - "the human belongs in positionality in a wholly other way than machine does. This way can become inhuman. This inhuman, however, is ever still inhuman. The human never becomes a machine"29.

A formas de tecnologia mais avançadas, que levam em conta a Inteligência artificial, não deixam de confirmar a ideia de Gestell. O Uber, por exemplo, é uma máquina que muda todas as relações - não apenas para quem usa ou está inscrito, mas para qualquer um. O homem, no caso, é levado a colocar a sua disponibilidade (de tempo e força) em favor da máquina (ou do capital). O capital é uma Gestell. O Uber é expressão da maquinação que mudou as nossas relações (de trabalho).

${ }^{27}$ Idem. Ibidem., p. 27.

${ }^{28}$ Idem. Ibidem., p. 35.

${ }^{29}$ Idem. Ibidem., p. 35. 
A Gestell, então, coloca tudo na disposição e muda as relações, ainda que sem contato. Não é uma posição psicológica, social. Mesmo assim, podemos sentir o "perigo" que está à espreita com a identificação e disseminação da Gestell na história da metafísica. Poderíamos sentir, como Schopenhauer sentiu, a força nos levando para o pessimismo. Poderíamos, de imediato, abraçar o niilismo. The Danger, próximo artigo das Conferências, nos mostra os detalhes da dominação da Gestell.

A Gestell concebida enquanto uma força, assim como o niilismo na história da metafísica, assim como a vontade de poder, retira a proteção da coisa ${ }^{30}$. Em sentido restrito, o mundo é o que guarda o Ser em sua essência. A guarda (wahrnis), diz Heidegger, é também a verdade (wahrheit). Aqui fica fácil e direta a ligação da Gestell com a Vontade de poder. Estamos tratando de duas maneiras de apontar para a "transmudação de valores", apenas aparentemente distintas, que suplantam, em última análise, a própria verdade. Assim como a vontade de poder, a mudança das relações causada pelas "desnaturações" da Gestell, desvelam o mundo, mudam a verdade. Aqui está o verdadeiro perigo: uma vez que tudo é colocado em jogo, tudo pode ser usado, inclusive o homem. Homens podem ser mortos em câmara de gás, rios podem ter seus cursos alterados, florestas são dizimadas, uma espécie de inseto pode desaparecer e dar lugar a um novo remédio para impotência e, claro, a disponibilidade (de tempo) do homem, seu anonimato, é suplantado completamente. $O$ perigo é a objetificação sem freios. A essência da posicionalidade é este perigo ${ }^{31}$. Em resumo:

\begin{abstract}
"According to its essence, technology, reigning of its own accord, is the gathering of positioning in the sense of a requisitioning into standing reserve of all that presences. The basic characteristic of this ordering positioning, however, essences in that pursuit in which beyng itself pursues its own essence with the forgetting of this essence. ${ }^{\prime 32}$
\end{abstract}

A característica "clássica" é jamais esquecer. É monotônica, como iremos mostrar mais a frente. Nesse sentido, a mudança que a Gestell imprime não é nada trivial. Sob certo ponto de vista, o texto A palavra de Nietzsche 'Deus morreu' e as Conferências de Bremen se mostram mais completos quando lidos conjuntamente, em especial enquanto projeto que diagnostica uma força disruptiva na metafísica. 0 fazem primeiro identificando essa tendência histórica com a morte do suprassensível

30 "In the essence of positionality, the unguarding of the thing as thing takes place". Idem. Ibidem., p. 45.

${ }^{31}$ Idem. Ibidem., p. 51.

${ }^{32}$ Idem. Ibidem., p. 63. 
e, depois, com a montagem da Gestell, que suplantam os valores, modificam as relações, desorganizam a verdade das coisas.

É possível agora perguntar: temos uma saída para isso tudo? Precisaríamos de um movimento de resgate da tradição, um movimento AntiGestell. "Du bist auf dem holzweg", que no livro primeiro analisado aqui é traduzido como "caminhos da floresta", significa propriamente "você está no caminho errado" ou "você está perdido". É preciso, portanto, identificar os caminhos errados e, claro, encontrar o caminho correto. Vamos notar agora que não foi apenas Heidegger que notou a maquinação humana em sua completa dimensão.

\section{O OUTRO}

Na obra Otherwise than Being, a distinção entre o Dizer e o Dito aparece como a marca da distinção que vem pautando nosso estudo da metafísica, entre a essência do Ser e objetos. Para Levinas, a transcendência não é alcançar o ser, mas o outro modo de ser. O que é o outro do ser? É algo definitivamente diferente do ser de outro jeito. Aqui também não se trata de "negar" classicamente as propriedades de um objeto ou pensar algo diferente.

Essa "negação" culmina em representação prévia - assim como a tematização perpetrada na Gestell. Logo, não poderia levar a lugar algum a não ser para longe do $\mathrm{Ser}^{33}$. Estaríamos saindo da vizinhança, para usar os temos do Heidegger. A história da metafísica, para Levinas, é povoada com o Dito:

"The history of philosophy, during some flashes, has known this subjectivity that, as in an extreme youth, breaks with essence. From Plato's One without being to Husserl's pure Ego, transcendent in immanence, it has known the metaphysical extraction from Being, even if, betrayed by the said, as by the effect of an oracle, the exception restored to the essence and to fat immediately fell back into the rules and led only to words behind the scenes." ${ }^{\prime 34}$

O dito não envolve o outro na sua estrutura lógica. Isto só pode querer dizer que a sua relação com a verdade (o ponto central da lógica), que ignora a liberdade,

\footnotetext{
33 "The good cannot become present or enter into a representation". Idem. Ibidem., p. 11.

${ }^{34}$ LEVINAS. Otherwise Than Being or Beyond Essence. Dordrecht, NE: Kluwer, 1997, p. 8. 
a responsabilidade, e carrega tudo para a noção de proposição. De fato, a própria noção de linguagem, que é "alargada" na história, apresenta um alargamento do poder do Dito, que nunca deixa, porém, de ignorar o que importa na transcendência, que é o outro que é o ser. A ontologia tradicional se prende no Dito e, como tal, ignora a essência do Ser.

Apenas o Dizer envolve o outro, essa parte ainda escondida, que só podemos "observar" quando ignoramos a estrutura óbvia da verdade, que está apenas no Dito. No Dizer, a questão não é a verdade, mas a responsabilidade (com o outro). Essa mudança para longe da verdade, em especial para pensar uma lógica dos discursos que aqui temos apresentados, é um ponto crucial.

De uma parte, não é possível ignorar as similaridades do projeto AntiGestell, niilista e AntiDito, que apresentamos até agora. Estamos, de todos os lados, na luta contra a representação, contra uma tematização "livre", contra a maquinação dos dispositivos criados na história da metafísica. O Dito, na sua concentração da verdade e esquecimento do outro, da essência do Ser, promove a violência da representação (assim como a Gestell). Nesta visão, o primeiro Wittgenstein está tão errado quanto o segundo: os dois esquecem da responsabilidade com o Outro. Não podemos reconhecer as regras do jogo sem representar e, naturalmente, sem modificar estas mesmas regras. A estrutura formal presente, a clássica, e o jogo de linguagem não podem ser abordados/jogados ignorando o outro!

Um ponto para ser observado aqui é o seguinte: diferente de Heidegger, Levinas não tem a pretensão pura de superação da subjetividade, ao menos esta subjetividade ligada ao pessoal, ao ego. Muito menos prega uma volta ao sujeito de predicados, ao modo fregeano. Os sentidos, a tematização, estão em serviço pelo outro na filosofia do Dizer. Os sentidos estão a serviço do testemunho. A estrutura kantiana da representação não é algo sem explicação, mas uma estrutura dada para reportar ao outro.

A proximidade, a vizinhança de Levinas, portanto, se dá pela completa permissão da substituição. O sujeito não é algo determinado por predicados, sim pelo outro. Admite-se que o sujeito é um pronome, indexicalmente colocado.

\section{A ESCRITA}

Derrida tem uma maneira própria de abordar esses elementos que, com certa permissão prática, modificam o meio, alteram a "realidade", inovam no mundo natural. Tanto na obra $A$ farmácia de Platão quanto n'A Gramatologia, Derrida expõe 
os contrastes entre escrita e fala como indício de um diagnóstico mais amplo, na direção dos dispositivos que temos destacados na análise de Nietzsche e Heidegger na história da filosofia.

A discussão na obra $A$ Farmácia de Platão se inicia com a leitura do diálogo Fedro, que por muito tempo foi ignorado como um texto de um Platão jovem, que ainda não tinha desenvolvido ideias filosóficas próprias. Sócrates conversa com Fedro e, em determinado momento, invoca a farmacéia para exemplificar um argumento perigoso, que nos leva para o abismo. Neste primeiro sentido, farmacéia é algo como um remédio. Seria esse uso puro fruto do acaso, questiona Derrida. Farmáceia, assim como "droga" em língua portuguesa, também tem o sentido corrente de veneno, tudo dependendo da dosagem. Em outro momento do diálogo platônico, Sócrates chama as folhas de escrita que Fedro carrega de "drogas para me fazer sair da cidade". É o outro sentido de phármakon que desponta: o de êxodo, de expulsão da cidade.

A associação da escrita com remédio, o veneno e a fuga da pátria, portanto, está estabelecida dentro da mesma raiz etimológica e também no contexto do diálogo. Para Derrida, a consideração é taxativa: a escrita é o phármakon ${ }^{35}$. No momento em que é apresentada, o rei egípcio, personagem do livro de Derrida, rejeita a escrita por reconhecer seu malefício. Rejeita como um pai rejeita um filho. O lógos, que é o pai da fala, não é o pai da escrita. A fala sem pai, sem lógos, é a escritura e exatamente por isso deveria ser rejeitada. Assim, essa desvinculação da escrita e presença, faz como que a escrita perca toda a importância para o discurso na visão de Derrida:

\footnotetext{
"Escrevendo o que não diz, não diria e, sem dúvida, na verdade jamais pensaria, o autor do discurso escrito já está instalado na posição do sofista: o homem da não-presença e da nãoverdade. A escritura é, portanto, encenação." ${ }^{\prime 36}$
}

A verdade aqui, longe da posição analítica-aristotélica, não é uma correspondência, mas uma vinculação. É presença, é proximidade, é rosto, para usarmos o termo de Levinas. Em outras palavras:

\begin{abstract}
"A verdade da escritura, ou seja, nós o veremos, a não-verdade, não podemos descobri-la em nós mesmo, por nós mesmos. E ela não é objeto de uma ciência, apenas de uma história recitada, de uma fábula repetida. Torna-se claro o vínculo da
\end{abstract}

\footnotetext{
35 DERRIDA. A Farmácia de Platão. São Paulo: Iluminuras, 2005, p. 17.

${ }^{36}$ Idem. Ibidem., p. 12.
} 
escritura com o mito, assim como sua oposição ao saber e especial ao saber que se colhe em si mesmo, por si mesmo."37

Se tem uma coisa que os tempos modernos, bombardeados por Gestell na forma de máquinas ultra avançadas, inteligências artificiais, é que a escrita é a fonte maior de mentiras, ainda que diga "a verdade". Apenas as manchetes viajam, perpassam algoritmos para enganar aqueles que querem informação demais, mas tem disposição de menos para interpretar. E nem toda disposição do mundo faria ultrapassarmos as barreiras impostas pelas tão faladas fake news. Não é uma questão sociológica ou psicológica: a escrita não tem o pai que protege o seu filho. Ainda que quiséssemos, o pai de uma notícia falsa não está disponível para revelação. $\mathrm{Na}$ verdade, onde tem escrita tem o parricídio, para usar um termo marcadamente derridiano. O pai é figura "matável" na escrita. Na fala, no debate, o pai está sempre pronto para corrigir, cobrar, explicar, e isto é algo que a escrita jamais terá. 0 paralelo entre fake news e mito não é por acaso, como saberia de imediato qualquer brasileiro que vive neste primeiro quarto do século XXI.

Não é preciso muito esforço para ver que o diagnóstico do niilismo, da metafísica do subjetivismo, da figura do Dito em Levinas e da maquinação, da força da Gestell, é o mesmo da escrita de Derrida. Heidegger tem duas passagens na $A$ palavra de Nietzsche 'Deus morreu' que deixa isso bem claro:

"O dito não significa, como se dissesse, a partir da negação e do pequeno ódio: não há nenhum Deus. O dito significa algo pior: Deus foi morto. Só assim se manifesta o pensamento decisivo."

"Cada comentário não tem apenas de captar o assinto do texto; tem também, sem chamar a atenção, de, a partir do seu assunto, acrescentar-Ihe imperceptivelmente, a partir do seu tema, algo de próprio. (...). Contudo, um comentário genuíno nunca compreende $\mathrm{o}$ texto melhor que seu autor $\mathrm{o}$ compreendeu, mas sim de outro modo." 38

Os trechos não poderiam ser mais conciliadores. Podemos acrescentar, contudo, que um texto nunca terá um "comentário genuíno" - o afastar do rosto é definitivo com o surgimento da maquinação da escrita. Tudo mudou! Nem o autor do

\footnotetext{
${ }^{37}$ Idem. Ibidem., p. 18.

38 HEIDEGGER. Os Caminhos da Floresta. Lisboa, PT: Fundação Calouste Gulbenkian, 1977, p. 248. 
texto é o real "dono" da interpretação - não está no controle da cadeia de sentidos imposto. Aqui nos vem à mente a historicidade da referência quando falamos de significado em Saul Kripke, como apresentado a terceira conferência do Naming and necessity. De fato, a palavra escrita, uma vez solta, está fora do controle de quem quer que seja.

Se formos honrar essa aproximação entre Gestell e o Phármankon, não podemos ignorar aquela terceira palavra, evitada por Platão no Fedro, e que precisamente por sua ausência desponta como um sentido importante, que é o pharmakós, o bode-expiatório, algo que afeta o curso natural das coisas na cidade grega. Quando a cidade parecia estar em maldição, precisava de livrar de algum problema não determinando, era escolhido um cidadão que iria ser morto, "levar a culpa" e livrar a cidade daquele problema. É a intervenção no curso natural:

\footnotetext{
"Comparou-se o personagem do pharmakós a um bode expiatório. O mal e o fora, a expulsão do mal, sua exclusão do corpo (e fora) da cidade, tais são as duas significações maiores do personagem e da prática do ritual"39
}

O movimento antiGestell é um movimento antipharmakós, que é, no final, contra o uso de maquinação para interferir artificialmente na proximidade. Ao invés de deixamos o rio ser o rio, fazemos hidrelétricas. A maquinação é contestada pela volta do bode expiatório a cidade - ou pelo menos com a sua não utilização. Pois, longe da verdade, a escrita se mantém por uma aparente facilidade, como, de fato, uma força (semelhante a Gestell): "operando por sedução, o phármakon faz sair dos rumos das leis gerais, naturais e habituais"40. Nesse sentido, nos parece que aqui existe uma mudança real da lógica adotada. A lógica clássica, escrita, simbólica, é uma contradição em seus próprios termos dentro do mundo modificado, sem pai. Não tomemos comprimidos para dormir, deixemos a insônia ser a insônia e o sono chegar quando tem que chegar. Só assim estaremos de fato na vizinhança do Ser. Só assim evitaremos o "mal" da maquinação e nos aproximaremos do ser. Ou, para usarmos a terminologia da Gramatologia, poderíamos reconstituir a presença frente ao suplemento ${ }^{41}$.

\footnotetext{
39 DERRIDA. A Farmácia de Platão. São Paulo: Iluminuras, 2005, p. 79.

40 Idem. Ibidem., p. 14.

${ }^{41}$ DERRIDA. Gramatologia. São Paulo: Perspectiva/EDUSP, 1973, p. 174.
} 


\section{A LÓGICA DA METAFÍSICA}

De tudo que foi pensando aqui, o maior enigma que ainda permanece é descobrir como que pode existir um sentido geral do que acontece na presença destes suplementos, destes dispositivos. Seria, a partir de agora, uma investigação da lógica. Ter uma lógica de um discurso é sempre algo interessante. Com uma lógica apropriada podemos, de plano, pensar em bases da linguagem utilizada, com seus termos principais, na semântica de base, em axiomas e teoremas importantes, nas propriedades metalógicas, relações com outros sistemas lógicos etc. E, em conjunto com as vantagens mencionadas, temos evidências textuais de que existe uma lógica a ser pensava para a visão da metafísica que temos tratado. Derrida pergunta na Gramatologia: "O que há com a voz na lógica do suplemento?"42. Heidegger afirma que o niilismo, em sua visão, é a "lógica intrínseca" da história ocidental, que culmina no declínio do ocidente ${ }^{43}$. Então, levando à sério o problema da lógica, para fazer algum senso formal dos discursos apresentados, temos alguns desafios.

O problema principal é que, quando estamos falando de lógica, temos alguns dogmas que devem ser usados ou muito bem justificados quando não se mostram pertinentes. A verdade é um destes dogmas. Pelo menos o é quando estamos no campo das lógicas conhecidas, em especial a lógica clássica. E o primeiro texto que apresentamos, A Palavra de Nietzsche 'Deus morreu', deixa muito claro que essa verdade "comportada", cujos conceitos podemos escrever e valorar, já não podem permanecer no contexto de transmudação dos valores. O niilismo tomou conta. A questão que se coloca agora é que lógica conhecida representa uma total transmudação dos valores, como propõe a filosofia de Nietzsche? A resposta é direta: absolutamente nenhuma. Ao modo da denúncia feita na apresentação no Do outro que é o ser de Levinas, parece que estamos perdidos no círculo vicioso de uma única negação possível, a do conjunto complemento. Sequer temos guarida quando partimos para o não-clássico. O não-clássico é também clássico, em certo sentido. Assim como as lógicas paraconsistentes do Newton da Costa constituem, em última análise, uma parte da lógica clássica, a negação enquanto parte da totalidade do outro não elimina a responsabilidade. Logo, não representa a transmudação dos valores. Como diz Nietzsche na Vontade de Poder: "temos a arte para não sucumbir a verdade". Como fazer lógica como arte e não mais como ciência? Este é o nosso verdadeiro desafio.

\footnotetext{
42 Idem. Ibidem., p. 201.

${ }^{43}$ HEIDEGGER. Os Caminhos da Floresta. Lisboa, PT: Fundação Calouste Gulbenkian, 1977, p. 258. 
Se convictos de que a lógica clássica não faz jus ao discurso do suplemento, é imperioso que façamos um passeio ao universo das lógicas para encontrar alguma que possa servir. Temos que investigar, de maneira abstrata, o que realmente caracteriza o dogma da verdade, pelo acúmulo de informações, e descobrir se existe uma alternativa.

\section{Lógica Universal e reflexões antimonotônicas}

Na pesquisa sobre a generalidade formal, não podemos ir mais fundo do que foram os pensadores da lógica universal. A resposta nos parece estar em algum lugar deste universo, ainda que oculta, não desvelada. Hilan Bensusan e Alexandre CostaLeite deram uma verdadeira guinada no mapeamento de lógicas com o artigo Logic and Their Galaxies ${ }^{44}$. Neste artigo é possível visualizar as fronteiras do que o raciocínio lógico pode parecer na sua mais profunda raiz. Em termos de prova, isto é, dos teoremas, uma lógica tem sua versão "normal", que prova tudo que tem uma prova e nada pode mudar isso. Este é o mundo comum. Esta mesma lógica tem a sua versão "anti", a antilógica, que prova algo se, e somente se, a lógica de referência não pode provar. Estamos falando em termos extremamente abstratos, sem pensar em alguma lógica particular. Se quisermos um exemplo básico, podemos pensar na lógica proposicional clássica não prova fórmulas atômicas, a forma mais básica de sua linguagem. Logo, a antilógica da lógica clássica tem fórmulas atômicas como teoremas. Tautologias, que são teoremas na lógica clássica, não são teoremas na antilógica da lógica clássica.

Muitas lógicas, inclusive a clássica que tomamos como exemplo, possuem propriedades tarskianas, que são de grande importância metalógicas e possuem grande importe filosófico. A monotonicidade é uma das propriedades tarskianas mais marcantes. Em linguagem natural, esta propriedade garante que todo argumento válido continua sendo valido mesmo quando adicionado novas premissas. 0 caso emblemático é a adição de premissas novas que contradizem alguma parte das premissas originais de um argumento válido. Em lógicas monotônicas adição de novas premissas não modificam a derivabilidade. Toda antilógica de uma lógica tarskiana, conforme demonstração de Béziau e Buchsbaum ${ }^{45}$, não possui nenhuma das queridas propriedades tarskianas. Em particular, essas lógicas são nãomonotônicas.

Lógicas não-monotônicas são lógicas que reconhecem que adições de premissa nem sempre são "inofensivas" para a derivabilidade. Existem

44 BENSUSAN, Hilan; COSTA-LEITE, Alexandre; DE SOUZA, Edelcio. "Logics and their galaxies." in The Road to Universal Logic. Birkhäuser, Cham, 2015. 243-252.

${ }^{45}$ BÉZIAU; BUCHSBAUM. Let us be Antilogical: Anti-Classical Logic as a Logic. Inédito. 
complementos, novas informações, que em verdade demandam revisão de velhas conclusões. Algumas informações mudam a relação (de consequência) de um sistema lógico. De um certo ponto de vista, com esse tipo de inovação problemática poderíamos pensar que estamos caminhando para longe da lógica da do complemento, que aceita de bom grado novas informações, novas verdades, e nos aproximando de uma lógica de do suplemento, que vê as inovações como marcas de um novo momento de significação. A fuga da monotonicidade é a mensagem do suplemento - é a subversão do valor de verdade. A verdade, a acumulação dentro da noção de argumento válido é o ponto forte do pensar clássico. O que acontece com a subversão disso tudo, porém, não é simplesmente a negação, como poderia ser uma lógica não-monotônica. Como a pista nos dada por Levinas, "apenas esse conjunto complemento", a força da negação clássica, não poderá nos encaminhar para aquele outro que é o Ser. Uma noção mais forte precisa ser levantada. Emerge, de imediato, a força do "anti" dentro das propriedades tarskianas. E se pensássemos em "antimonotonicidade"? Não se trata de um caso em que a monotonicidade falha. O raciocínio monotônico pode falhar por maneiras que nada teriam de ligação com o suplemento. Assim como Heidegger critica Nietzsche por não conseguir fugir da metafísica com seu niilismo que abre espaço para vontade de poder, as lógicas nãomonotônicas tentam fugir do império da verdade, dos dispositivos disruptivos inquestionáveis, sem qualquer sucesso. Ainda estão perdidos no mundo clássico, apenas "cavando" exceções. Não é uma força, é, no máximo, uma Tekné.

No artigo Paraconsistentization through antimonotonicity: towards a logic of supplement ${ }^{46}$, a tentativa é transformer o insight não-monotônico em uma força capaz de fazer as vezes da lógica do suplemento. Não só foi possível formular as noções de suplemento ao modo da lógica universal, como o aparato formal em torno da monotonicidade mostrou que a antimonotonicidade era uma peça fundamental para entender o papel estrutural das novas premissas dentro de um argumento, em todos os seus detalhes. Raciocínios antimonotônicos são aqueles cuja a derivabilidade é prejudicada por qualquer adição extra de premissas. Apesar de parecer apenas um caso geral de não-monotonicidade, a conjectura de argumentos que não podem ser "melhorados" por novas premissas cria uma série de questões filosóficas e lógicas que não estão presentes na lógica não-monotônica comum. Dentro das lógicas antimonotônicas, podemos pensar que tipo de argumentos realmente valem. Descobrimos que todos os argumentos das lógicas são minimais, isto é, contém o menor número de premissas possível para manter a derivabilidade. Não tem

${ }^{46}$ BENSUSAN, Hilan; CARNEIRO, Gregory. Paraconsistentization through antimonotonicity: towards a logic of supplement. In: Costa-Leite, Alexandre (ed.). Unlimited Consequence. London: College Publications, 2020. 
premissas "extras", algo que pode ficar sem uso na prova. As lógicas antimonotônicas também são paraconsistentes, pois não derivam qualquer coisa na presença de contradições. Isto é fácil de ver, pois muitas provas por ex falso quodlibet em uma dada lógica podem ser substituídas por provas menores, que dispensam o uso da negação, por exemplo. Temos que a força da explosão, e por consequência da negação clássica, está suprimida nas lógicas antimonotônicas. É paraconsistente, mas com a vantagem de não precisar de qualquer manipulação de negações para ser formulado.

Em geral, assim como a hidrelétrica muda a relação com o rio no discurso do suplemento, as lógicas antimonotônicas não suportam adições supérfluas aos seus argumentos. A relação com a derivabilidade muda como a do rio, o que nos leva a crer que as lógicas antimonotônicas sejam o caminho mais curto para a formalização do discurso do suplemento.

Enquanto força, o suplemento quer mudar toda a história, todas as relações, todos os valores - os valores de todas as variáveis. É a completa mudança. Como diz Nietzsche: "A questão dos valores é mais fundamental que a questão da certeza". A centralidade do suplemento dentro das lógicas antimonotônicas é a completa corrupção da derivabilidade. Estamos pensando, então, no tipo de lógica que não suporta mais premissas. A partir do momento em que se coloca mais informação, mais objetos, se "dispara" o suplemento se muda a relação de consequência - assim como a hidrelétrica, enquanto Gestell, muda a relação com o rio. Nada mais é derivado com a posição de novas premissas em argumentos válidos - este é o espírito da lógica do suplemento. Se isso vai fazer com que a verdade deixe de ser o valor dominante, isso é uma questão de depende de verificações futuras. É possível, contudo, que estejamos certo de que não exista uma lógica até hoje que não tenha sucumbido à verdade. Contudo, a harmonia verificada entre as modificações implementadas na direção da lógica do suplemento e algumas questões dentro da lógica universal denotam que o debate no conteúdo metafísico da lógica pode ir muito além dos debates em torno da referência, da verdade e das modalidades. Isto por si já é um desenvolvimento que vale o debate. Da parte metafísica, a antimonotonicidade, no artigo apresentado, desvenda a confusão complicada que não nos permitia falar em niilismo, Gestell ou mesmo o outro que é o Ser em termos de negação clássica. De fato, existem peculiaridades dentro da história da metafísica que não podem ser organizadas com a abordagem comum da lógica universal. Apenas pesquisas futuras dirão quanto a lógica do suplemento reforçará o discurso metafísico da forma como apresentamos, qual a semântica devemos apresentar, uma vez que a verdade é de difícil adequação filosófica, bem como o quão longe 
poderemos ir na compreensão do tema da monotonicidade, que até a apresentação das lógicas antimonotônicas tinham seu conteúdo filosófico limitado.

\section{BIBLIOGRAFIA}

BENSUSAN, Hilan; CARNEIRO, Gregory. Paraconsistentization through antimonotonicity: towards a logic of supplement. In: Costa-Leite, Alexandre (ed.). Unlimited Consequence. London: College Publications, 2020.

BENSUSAN; COSTA-LEITE; DE SOUZA. "Logics and their galaxies." In The Road to Universal Logic. Birkhäuser, Cham, 2015. 243-252.

BÉZIAU; BUCHSBAUM. Let us be Antilogical: Anti-Classical Logic as a Logic. Inédito. CÉSAR. La guerre des gaules. Paris, França: GF Flammarion, 1964.

DERRIDA. A Farmácia de Platão. São Paulo: Iluminuras, 2005.

HEIDEGGER, M. Os Caminhos da Floresta. Lisboa, PT: Fundação Calouste Gulbenkian, 1977.

HEIDEGGER, M. Metaphysics AS History of Being in The end of Philosophy. Chicago: The University of Chicago Press, 1973.

HEIDEGGER, M. Bremen and Freiburg Lecutres. Indiana, USA: Indiana University Press, 2012.

LEVINAS. Otherwise Than Being or Beyond Essence. Dordrecht, NE: Kluwer, 1997. 